\title{
Neuropsychological and Electrophysiological Evaluation after Rape: A Case Study of a Teenage Girl
}

\author{
Lucía Ester Rizo-Martínez¹, Miguel Ángel Guevara1, Luis Francisco Cerdán1, \\ Francisco Abelardo Robles-Aguirre ${ }^{2}$, Araceli Sanz-Martin1, Marisela Hernández-González1 \\ ${ }^{1}$ Instituto de Neurociencias, CUCBA, Universidad de Guadalajara, Guadalajara, Jalisco, México \\ ${ }^{2}$ Centro Universitario del Norte, Universidad de Guadalajara, Colotlán, México \\ Email: lucyrizomar@hotmail.com
}

Received 18 April 2014; revised 31 May 2014; accepted 16 June 2014

Copyright (C) 2014 by authors and Scientific Research Publishing Inc.

This work is licensed under the Creative Commons Attribution International License (CC BY).

http://creativecommons.org/licenses/by/4.0/

c) (i) Open Access

\begin{abstract}
Although rape is an event with a high incidence worldwide, there is currently no single consensus about both the general effects and the diagnosis and treatment of this. To evaluate the consequences of rape, a teenage girl was evaluated at two moments: a month-and-a-half and then a year-and-a-half after being raped. Clinical measurements, neuropsychological testing and electroencephalographic recording (EEG) were conducted in four conditions: eyes closed, eyes open, and during performance of two tasks: Towers of Hanoi and Wisconsin. Observations showed subsyndromal symptoms of post-traumatic stress on the first evaluation, and close-to-normal scores on the neuropsychological and cognitive tests in both assessments. Decreased cortical EEG synchronization, mainly in the fast frequencies and in almost all conditions, was obtained in the second evaluation. The results obtained in this study may indicate an early development in the brain, which is discussed in light of current literature on this topic.
\end{abstract}

\section{Keywords}

Rape, Adolescence, EEG, Clinical Evaluation, Neuropsychological Testing

\section{Introduction}

The World Health Organization (WHO, 2002) defines sexual violence as any sexual act, attempt to obtain a sexual act, unwanted sexual comments or advances, or acts to traffic with, or otherwise operated, against a person's sexuality using coercion, by any person, regardless of their relationship to the victim, and in any setting. 
The WHO further states that sexual violence occurs throughout the world [1] that adolescents and young adult women are four times more likely to be victims of sexual assault than women in all other age groups [2], and that the probability of a woman being a victim of rape/attempted rape during her lifetime may be as high as $42 \%$ [3]-[5]. Sexual violence has been reported to have a profound impact on physical and mental health in both the short and long term [1]. The most frequently reported symptoms are depression, anxiety, dissociation, behavioral disorders, aggressiveness, inappropriate or early sexual behavior and activity, loss of self-esteem, prostitution, delinquent behavior, suicide or attempted suicide, and symptoms of post-traumatic stress disorder (PTSD) [6]-[10], which are manifested in varying percentages of victims. Of course, not all individuals show the same symptoms, so effects depend on several factors. Some studies suggest, for example, that there are critical periods in the development of the individual when experiences of stress can induce certain effects on brain development, depending on the age at which the event occurs [11] [12]. Other factors to be considered are the time of exposure to the stressful stimuli and the intensity of the event. A study [13] found that adolescents who experienced more acute negative events and chronic life stressors but lacked stable social resources showed worse psychosocial functioning. Also, prolonged stress is a major risk factor for depression [14]. Another aspect judged to play an essential role is the subject's sense of control over the stressor [15]. Regarding the neurobiological effects of stress during development, it has been suggested that physical or sexual abuse during childhood could be associated with limbic hyper-excitability [16], unregulated hypothalamic-pituitary-adrenal responses [17], diminished left hemisphere and left hippocampal development [18] [19], and alterations of the functionality of certain brain structures, such as the amygdala, hippocampus, prefrontal cortex, temporal lobule, supra-marginal gyrus, anterior cingulate cortex, parietal cortex, and motor cortex, among others [20] [21].

One way to assess brain functionality is through the use of quantitative EEG techniques such as coherence (coh) and correlation ( $r$ ) analyses, two methods that are considered equivalent both evaluate the degree of similarity between two EEG signals though they use distinct mathematical calculations [22] [23]. The coh measure is sensitive to changes in amplitude and power as well as variations in phase relationships; whereas $r$ is sensitive to phase and polarity, independent of amplitude [24]. Though few studies have evaluated the degree of EEG coupling in relation to sexual violence, an increase in left intrahemispheric (INTRA) coh compared to controls has been reported [25] [26], as has a marked frontal interhemispheric (INTER) coh asymmetry [27]. Other research has reported cognitive deficits including poor performance on memory tasks [28], attention measures, and abstract reasoning/executive function [29] after an experience of sexual violence.

This study reports the case of a teenage girl who was a victim of rape on two occasions. She was assessed by clinical and neuropsychological testing and EEG recording at two moments: a month-and-a-half and then a year-and-a-half after the second event. The decision to perform the second assessment was taken for two reasons: first, since this teenager showed very few symptoms on the first evaluation, it was thought that some symptoms might appear later; second, to determine differences and similarities between the EEG recordings and cognitive parameters from the two evaluations.

\section{Method}

\subsection{Case of Study}

Yatzil (pseudonym) is a right-handed teenage Mexican adolescent (Table 1) who was raped on two occasions. The first occurred when she was six years old. She says that the man was in his early 30s and appeared to be on drugs. As she said nothing to her family, no complaint was registered, and she received no assessment or other attention. Her second rape occurred at the age of 14, as she walked to school at about 6:30 in the morning. The man who attacked her ran by her once and then returned to threaten her, holding a knife to her throat. He forced her into a parking lot where he raped her. The attacker was in his late 20s but was not drugged or inebriated. After the attack, she went to school as usual and attended class as if nothing had happened, but she told a classmate what had transpired. The student told a teacher who informed Yatzil's mother. They went for medical attention and to register a complaint.

\subsection{Clinical History}

Yatzil's mother is 50 years old. She studied only up to the fourth grade of primary school and currently works as a merchant. Her father is 47. He finished grade eight and is an industrial mechanic. Yatzil is her mother's fourth 
Table 1. Demographic characteristics of Yatzil.

\begin{tabular}{cc}
\hline Characteristics & Data \\
\hline Age (years) & 14 first evaluation, 15 second evaluation \\
Gender & Female \\
Weight & 61 \\
Height (cm) & 154 \\
Handedness (right/left) & Right \\
Birth weight (kg) & 2.300 \\
Birth height (cm) & 45 \\
Birth (full term/premature) & Full term \\
Nationality & Mexican \\
Age of first rape & 6 years \\
Age of second rape & 14 years \\
Socioeconomic status & lower middle class \\
\hline
\end{tabular}

$\mathrm{Kg}=$ kilograms; $\mathrm{cm}=$ centimeters.

daughter, second with this father, who is the mother's third partner, but the only one she married. Yatzil's mother has been physically or psychologically abused by all her partners.

When Yatzil's mother was pregnant with her, she had many problems with her partner and was often depressed and angry. She almost miscarried on three occasions. At birth (full term, cesarean section) Yatzil had serious problems with choking and had to spend four days in hospital. She weighed about 2 kilos, 300 grams and measured $45 \mathrm{~cm}$; her mother breastfed her for less than a month. From birth Yatzil was constantly rejected by her father because he hoped for a boy. Shortly afterwards he left the home and Yatzil has had almost no contact with him throughout her life. She recalls that her father and mother often fought. With respect to such events as the age at which Yatzil began to walk, talk and learn sphincter control, her development was typical of the norms of that time.

At present Yatzil is a healthy girl and she is known as a very friendly girl. She had her first boyfriend at 12 in a relation that lasted three months. She has had three boyfriends, but no voluntary sexual intercourse with any of them, or anyone else. Yatzil is currently studying her first semester of high school. She has good grades, many friends, and good relationships with her teachers. She began kindergarten at three and adapted quickly. She has always enjoyed school, has never failed, and there is no evidence of complaints about her behavior in the schools she has attended up to now. She wants to study medicine.

\subsection{Procedure}

Permission was obtained from the Chief of Emergency Pediatrics and Coordinator of the Multidisciplinary Group for Child Victims of Abuse at the Civil Hospital "Dr. Juan I. Menchaca”, Guadalajara, Jalisco, Mexico, and informed consent was obtained from the victim and her mother for the assessment. Furthermore, the protocol for this study was approved by the Ethics Committee of the Institute of Neurosciences of the University of Guadalajara.

The teenage girl was evaluated at two moments: a month-and-a-half and then a year-and-a-half after the second rape. Each of the evaluations consisted of two sessions (lasting approximately one hour each one): a session in which clinical and neuropsychological tests were applied and another in which an electroencephalographic recording was performed. The evaluation included clinical interviews with both women (mother and daughter) and application of the following clinical scales: the Children's Depression Inventory (CDI), the Trait Anxiety Inventory for Children (STAIC), and the Children's Post-Traumatic Stress Scale (CPSS). Also, we applied the vocabulary and block design subsets of the Wechsler Intelligence Scale for Children (WISC-IV-R) to estimate IQ [30], and the handedness items from the Edinburgh Handedness Inventory [31] [32]. Yatzil was de- 
fined as right-handed. Some sub-tests from the Child Neuropsychological Assessment Battery for Spanishspeaking Children (Evaluación Neuropsicológica Infantil, ENI) [33] were used to evaluate attention and memory, and she was asked to perform computerized versions of the Tower of Hanoi task (HANOIPC3) [34] and the Wisconsin Card-Sorting Test (WCST) and the Wisconsin Card-Sorting Test (WCST).

\subsection{EEG Recording}

EEGs recordings were taken during both evaluations with the participant awake, in a sitting position, in a dimly-lit, soundproof room, with her head supported by the back of a comfortable chair, and in four conditions: eyes closed ( $3 \mathrm{~min}$ ), eyes open ( $3 \mathrm{~min}$ ), at rest, and during performance of the Tower of Hanoi (maximum $7 \mathrm{~min}$ ) and Wisconsin tasks (approximately $15 \mathrm{~min}$ ). The recording sites were Fp1, Fp2, F3, F4, P3 and P4, according to the 10 - 20 International System [35]. All derivations were referred to linked ears, while the ground electrode was placed on the forehead. EEGs were amplified using a Grass model P7 polygraph with EEG filters set at 1 and 60 Hz. Impedance for the EEG electrodes was kept below $10 \mathrm{~K} \Omega$.

Specially-designed software [36] was used to sample (1024 points at a sample rate of $512 \mathrm{~Hz}$ ) and store the EEG data for off-line processing. All EEG epochs that were visually identified as contaminated by noise were automatically removed by another computer program (CHECASEN) [37]. The EEGs were analyzed using the Potencor program [38] that applied the Fast Fourier Transform and Pearson product-moment correlation. Calculations included INTER $r$ and coh between homologous left and right derivations (Fp1 - Fp2, F3 - F4, P3 - P4) and INTRA $r$ and coh between derivations in the left (Fp1 - F3, Fp1 - P3, F3 - P3) and right hemispheres (Fp2 F4, Fp2 - P4, F4 - P4) for seven frequency bands: delta $(\delta, 1.5$ - $3.5 \mathrm{~Hz})$, theta $(\theta$, $3.5-7.5 \mathrm{~Hz})$, alpha $1(\alpha 1,7.5$ $10.5 \mathrm{~Hz})$ alpha $2(\alpha 2,10.5-13.5 \mathrm{~Hz})$, beta $1(\beta 1,13.5-19.5 \mathrm{~Hz})$ beta $2(\beta 2,19.5-30 \mathrm{~Hz})$ and gamma $(\gamma, 30.5-$ $60 \mathrm{~Hz})$.

\section{Results}

\subsection{Clinical Test Results}

Children's Depression Inventory (CDI): A score of 19 or higher indicates depressive symptoms. Yatzil scored 8 on the first evaluation and 3 on the second, indicating low depressive symptomatology (Table 2). Trait Anxiety Inventory for Children (STAIC): A score of above 60 is considered a high level of anxiety. On both evaluations, Yatzil scored 30, suggesting a low level of anxiety (Table 2). Children's Post-traumatic Stress Scale (CPSS): To judge the presence of PTSD, the criteria of the Diagnostic and Statistical Manual of Mental Disorders (DSM-IV) were applied to detect at least one symptom of re-experiencing, 3 of avoidance, and 2 of increased activation [39], the standards for diagnoses of subsyndromal PTSD [40]. We considered a symptom to be present when it occurred at a high frequency and on most days. On evaluation 1, Yatzil showed one symptom of re-experiencing and 3 of increased activation, sufficient to be considered subsyndromal at that time. On assessment 2, she once again showed some signs of re-experiencing and activation, but they were not sufficiently frequent to count as symptoms; thus, the determination was that neither PTSD nor subsyndromal PTSD was present (Table 2).

Table 2. Summary of clinical symptoms.

\begin{tabular}{lll}
\hline \multicolumn{1}{c}{ Clinical Scales } & \multicolumn{1}{c}{ First evaluation } & \multicolumn{1}{c}{ Second evaluation } \\
\cline { 2 - 3 } & \multicolumn{1}{c}{ Scores } & \multicolumn{1}{c}{ Scores } \\
\hline Children's Depression Inventory (CDI) & $8 / 19$ & $3 / 19$ \\
Trait Anxiety Inventory for Children (STAIC) & $30 / 60$ & $30 / 60$ \\
& Symptoms presented & Symptoms presented \\
Children's Post Traumatic Stress Scale (CPSS) & 1-re-experiencing symptom & 0-re-experiencing symptom \\
& 0-avoidance symptom & 0-avoidance symptom \\
3-increased activation \\
(PTSD** not present)
\end{tabular}

Bold numbers $=$ Minimum score to consider that the disorder is present. ${ }^{* * P T S D}$ diagnosis present $=$ At least 1 re-experiencing symptom, 3 of avoidance symptom AND 2 of increased activation. *Subsyndromal PTSD diagnosis present = At least 1 re-experiencing symptom, 3 of avoidance symptom OR 2 of increased activation. 


\subsection{Neuropsychological Test Results}

Wechsler Intelligence Scale for Children (WISC-IV-R): On evaluation 1, Yatzil obtained an IQ of 82; on the second her result was 91 (Table 2). Child Neuropsychological Assessment Battery for Spanish-speaking Children: Yatzil obtained average scores on almost all sub-tests, except for Digits in progression, where her result was just 2 (extremely low) on the first assessment. On the text memory task she obtained 9 (low) on assessment 1 and 5 (low) on evaluation 2 (Table 3). In this battery, natural scores are converted to their equivalent in percentiles. Tower of Hanoi (HA): She achieved practically identical scores on both evaluations, but was unable to complete the task on both occasions (Table 3). Wisconsin (WI): Yatzil completed all the possible categories on both assessments (6/6) and her execution was virtually identical both times (Table 3).

Table 3. Summary of neuropsychological data.

\begin{tabular}{|c|c|c|}
\hline Test & First evaluation & Second evaluation \\
\hline \multicolumn{3}{|l|}{ Tower of Hanoi } \\
\hline First movement latency & $4.2 \mathrm{sec}$ & $4.2 \mathrm{sec}$ \\
\hline Total movements & 132 & 121 \\
\hline Total correct movements & 64 & 62 \\
\hline Total incorrect movements & 68 & 59 \\
\hline Complete or incomplete task in the time given ( 7 minutes) & Incomplete & Incomplete \\
\hline \multicolumn{3}{|l|}{ Wisconsin Card Sorting Test (WCST) } \\
\hline Total stimuli presented & 87 & 107 \\
\hline Total correct answers & $67,77 \%$ & $80,74.8 \%$ \\
\hline Total incorrect answers & $20,23 \%$ & $27,25.2 \%$ \\
\hline Finished sequences & $6 / 6$ & $6 / 6$ \\
\hline Total of perseverations & $12,13.8 \%$ & $9,8.4 \%$ \\
\hline \multicolumn{3}{|c|}{ Child Neuropsychological Assessment, Battery for Spanish-speaking Children* } \\
\hline \multicolumn{3}{|l|}{ Visual attention } \\
\hline Cancellation of drawings & 63 (average) & 75 (average) \\
\hline Letter cancellation & 26 (average) & 50 (average) \\
\hline \multicolumn{3}{|l|}{ Auditory attention } \\
\hline Forward digit span & 2 (extremely low) & 63 (average) \\
\hline Backward digit span & 4 (average) & 16 (low average) \\
\hline \multicolumn{3}{|l|}{ Auditory verbal memory } \\
\hline Word List & 50 (average) & 26 (average) \\
\hline Test memory & 9 (low) & 5 (low) \\
\hline
\end{tabular}

*Scores converted to percentiles.

\subsection{EEG Recording Results}

Considering that some studies [41] [42] indicate that no major EEG changes occur between 14 and 15 years of age, this study only considered differences significant if they showed a change (increase or decrease) $\geq 40 \%$ on evaluation 2 (E-2) compared to evaluation 1 (E-1). In general, both INTER $r$ and coh Fp1 - Fp2 and F3 - F4 (Figure 1(a), Figure 1(b)), showed decreases mainly in the fast frequencies on E-2, compared to E-1. No differences were found in INTER $r$ or coh P3 - P4 (Figure 1(e), Figure 1(f)). 

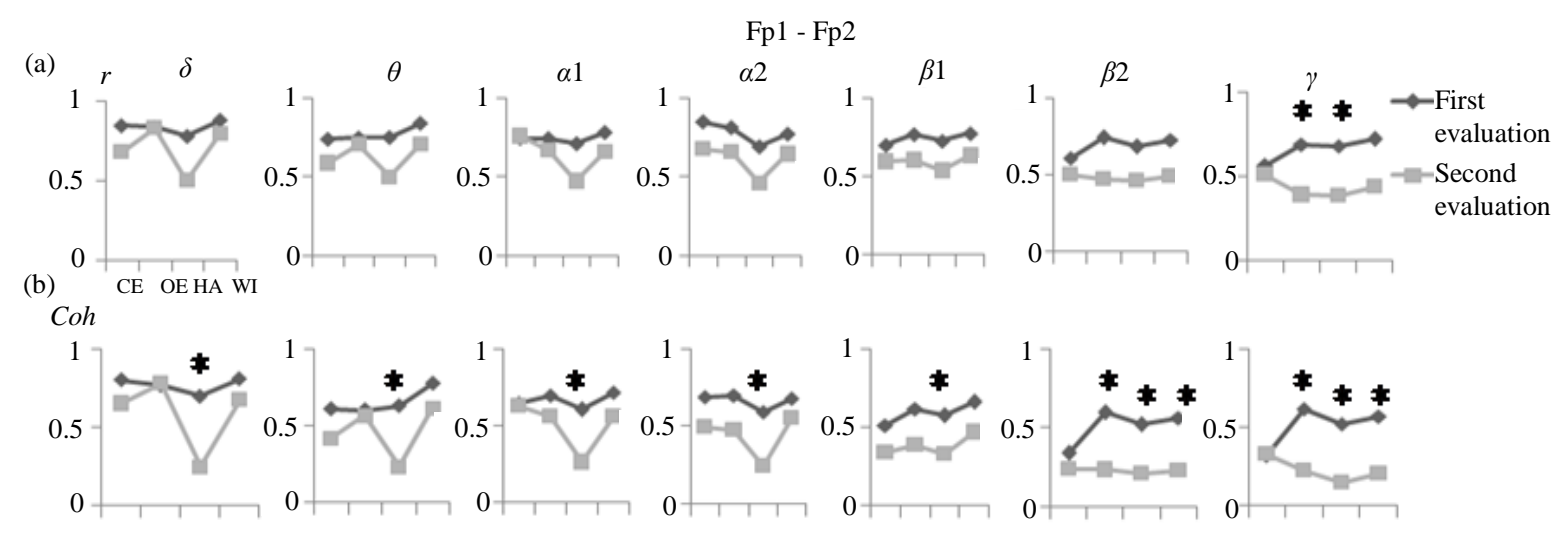

Coh

(c)
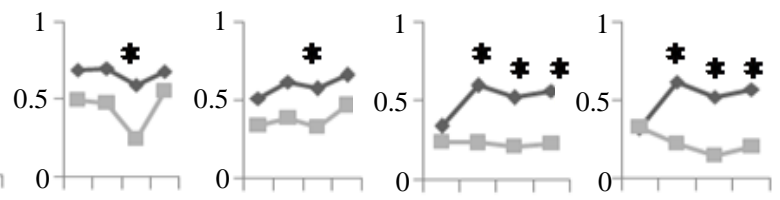

F3 - F4
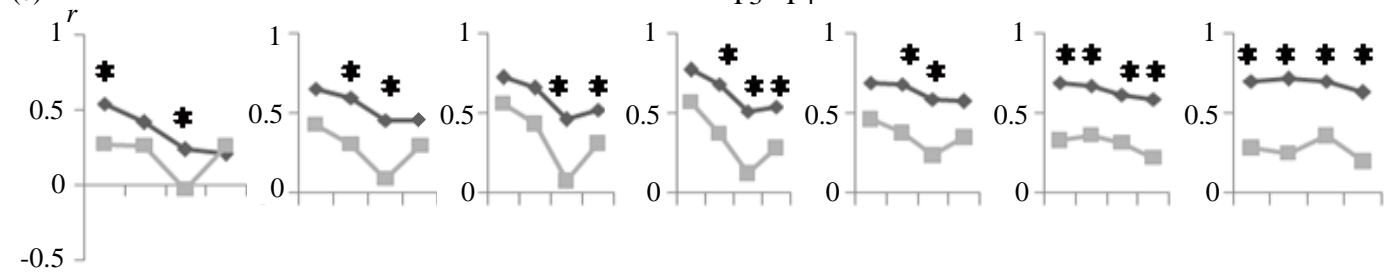

(d)Coh

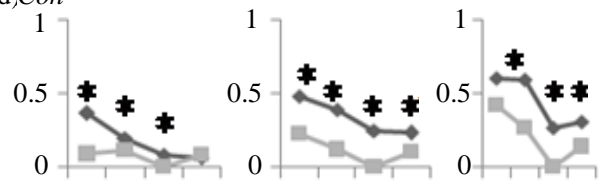

(e)
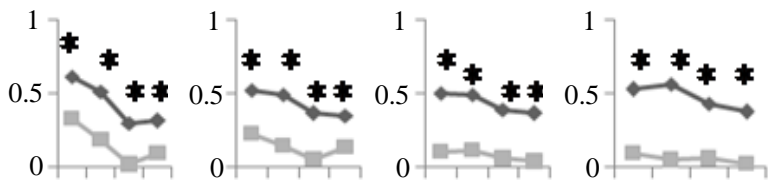

P3 - P4
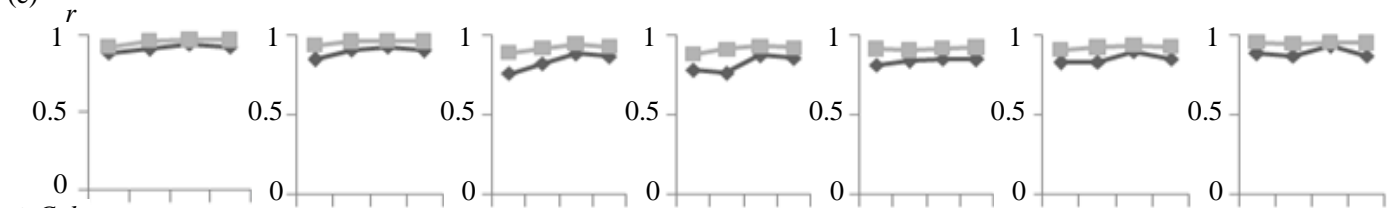

(f) $\mathrm{Coh}$
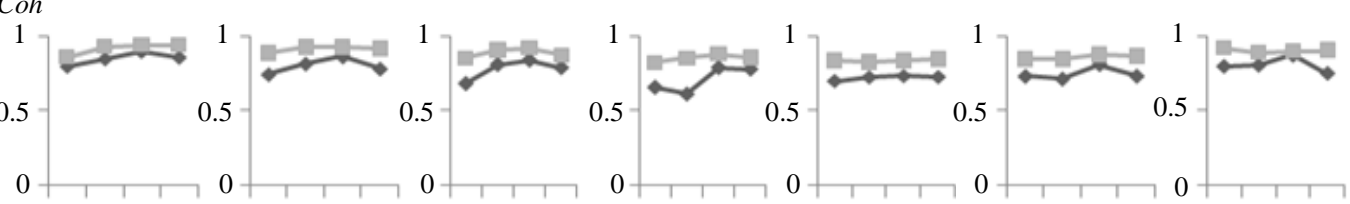

Figure 1. Values of INTER $r$ and coh (Fp1 - Fp2 [a y b], F3 - F4[c y d] and P3 - P4 [e y f]) in all bands and in all four conditions: eyes closed (EC), eyes open (EO), and during performance of the Hanoi (HA) and Wisconsin (WI) tasks in both evaluations. * $\geq 40 \%$ compared to evaluation 1 .

With respect to left INTRA $r$ and coh Fp1 - F3 (Figure 2(a), Figure 2(b)), there were increases in the slow bands in the WI and HA conditions, with a decrease in the fast bands on E-2 compared to E-1. Only INTRA $r$ Fp1 - P3 (Figure 2(c)) showed decreases in delta during HA and WI and in the faster bands in all conditions. INTRA $r$ and coh F3 - P3 (Figure 2(a), Figure 2(b)), meanwhile, had significant decreases in almost all frequencies and conditions compared to evaluation 1 (Figure 2(e), Figure 2(f)).

In right INTRA $r$ and coh, Fp2 - F4 (Figure 3(a), Figure 3(b)) and Fp2 - P4 (Figure 3(c)) a decrease on evaluation 2 with respect to E-1 in some conditions, mainly in the fast bands. In INTRA $r$ and coh F4 - P4 (Figure 2(a), Figure 3(b)), a decrease of the fast frequencies was obtained mainly during the task conditions (Figure 3(e), Figure 3(f)).

\section{Discussion}

This is a peculiar case study because despite being raped twice in her life, Yatzil seems not to have been 


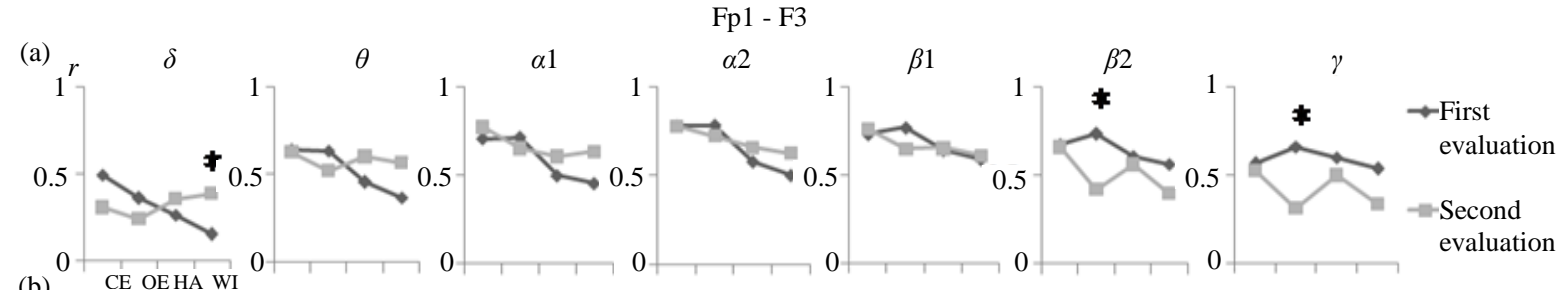

(b)

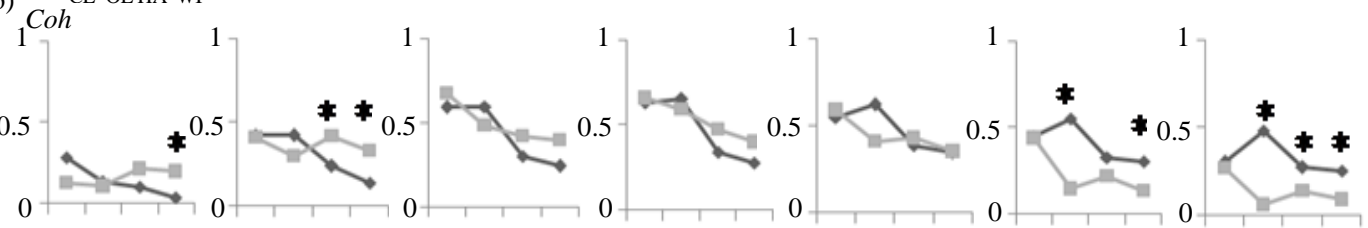

(c) $r$

Fp1 - P3

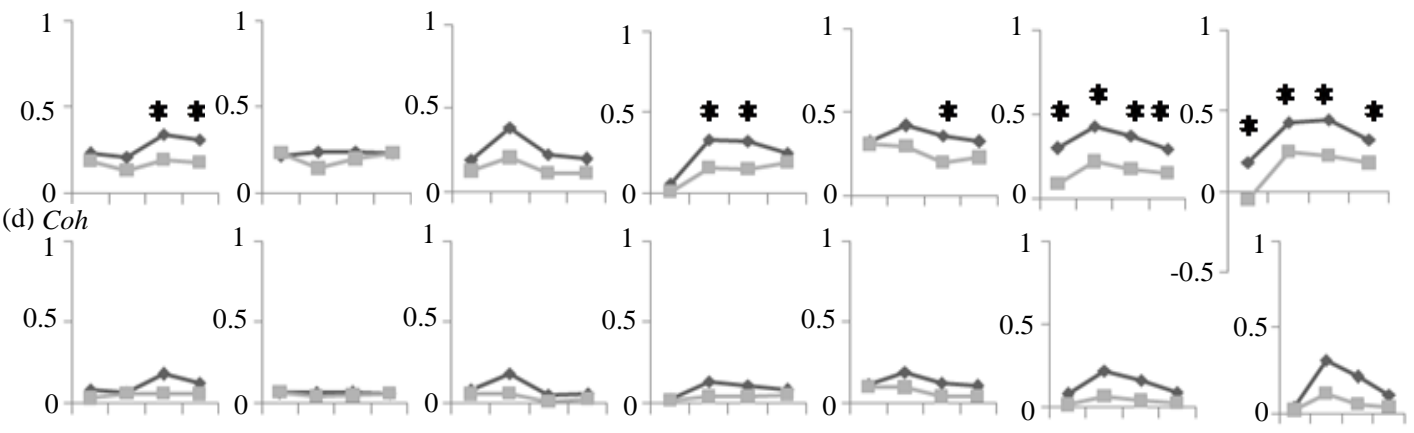

(e)

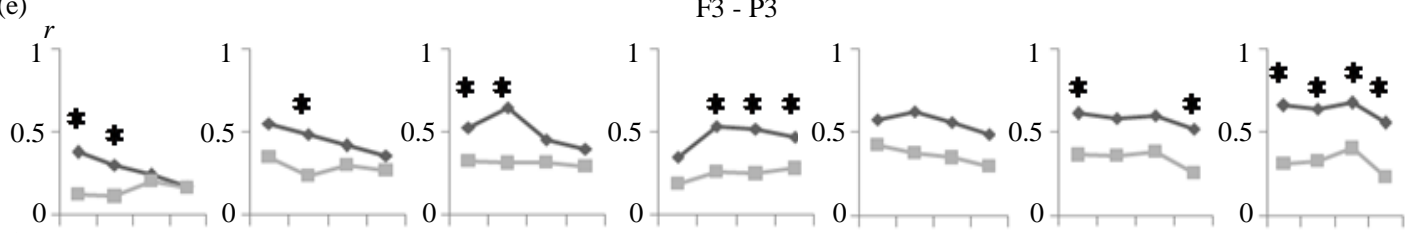

(f) $\mathrm{Coh}$
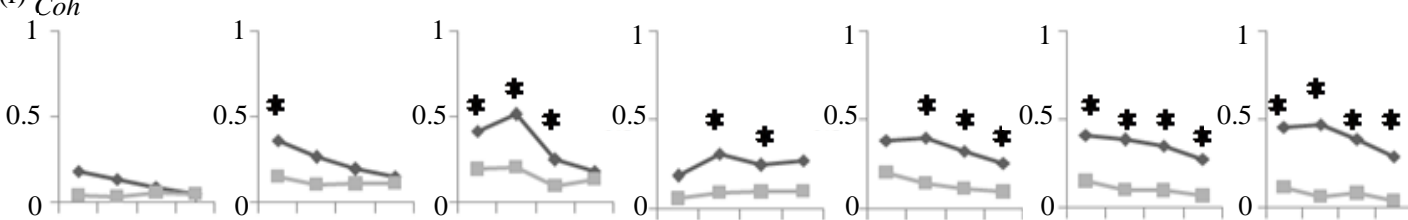

Figure 2. Values of left INTRA $r$ and coh (Fp1 - F3 [a y b], Fp1 - P3 [c y d], and F3 - P3 [e y f,) in all bands in the four conditions: eyes closed (EC), eyes open (EO), and during performance of the Hanoi (HA) and Wisconsin (WI) tasks on both evaluations. $* \geq 40 \%$ compared to evaluation 1 .

seriously affected, at least not in the areas evaluated in this work. Her life history presents many aspects that would seem to constitute severe disadvantages for her personal development: namely, low birth weight, problems at birth, medium-low socioeconomic status, absent father, her mother's chronic depression, and family disintegration. However, potential advantages in her life, such as her good relationship with her mother and the sister that lives with them, as well as the absence of parental abuse, might be sufficient to offset possible psychopathologies [43] or adverse personality traits. In general, the data from this study show that several areas of Yatzil's life appear to be unaffected by the violent events that she has experienced. Thus, it is possible to suggest that Yatzil develope a high level of "resilience", a term that refers to a class of phenomena characterized by good outcomes despite serious threats to adaptation or development [44].

On the cognitive assessment, Yatzil also achieved good performance, except for execution of the Towers of Hanoi task, which she was unable to complete in the time allowed on the two evaluations. Likewise, her scores on the digits in progression sub-test were extremely low on E-1 and low on the text memory task on both assessments; however, there is no way of knowing whether these deficiencies are due to the rapes that she suffered 


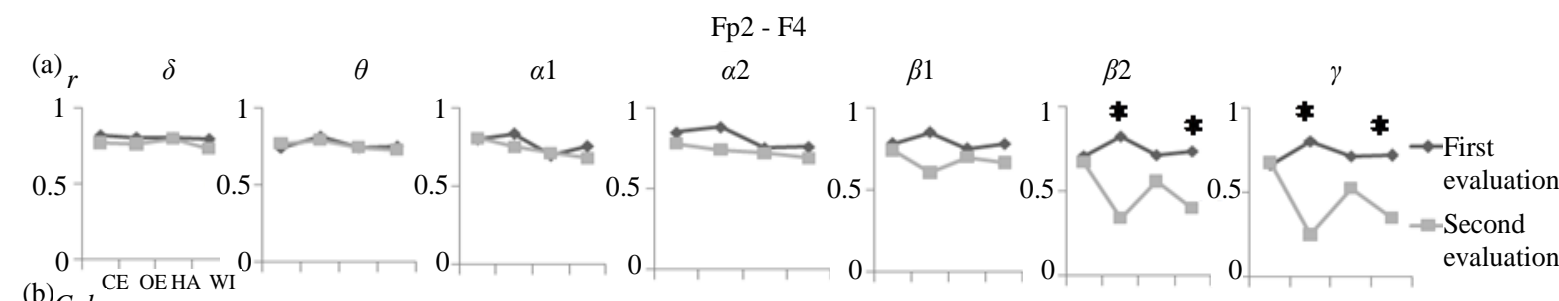

(b) $\mathrm{Coh}$
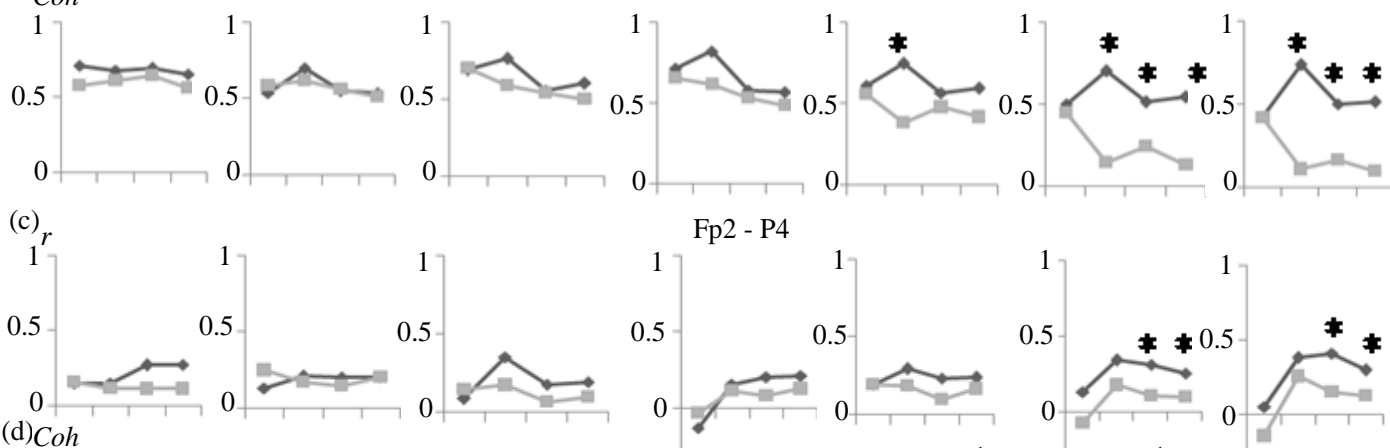

Fp2 - P4
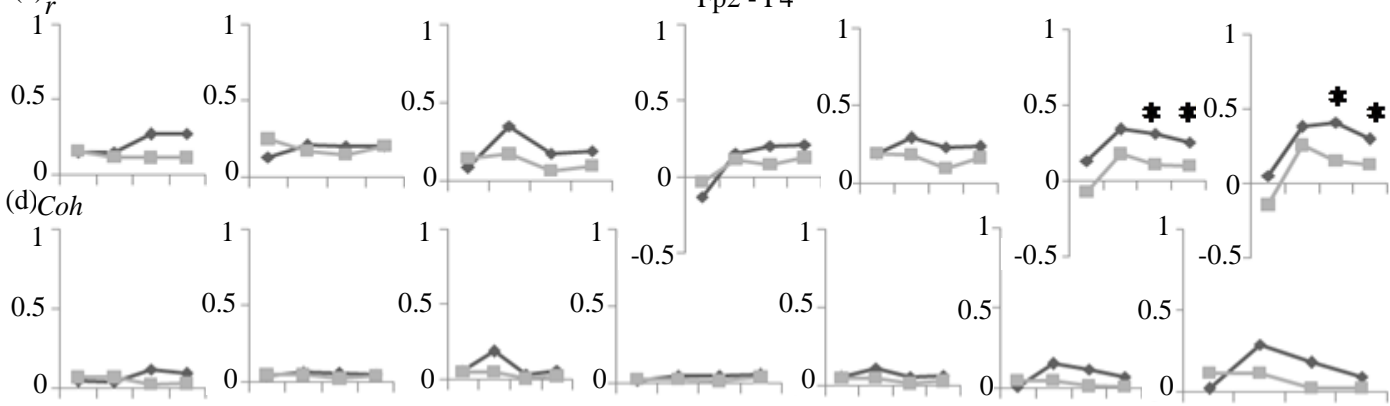

(e)

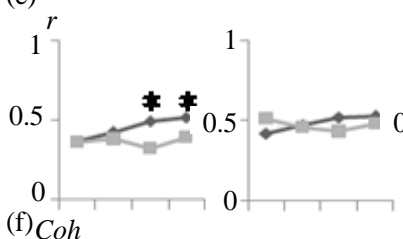

F4 - P4
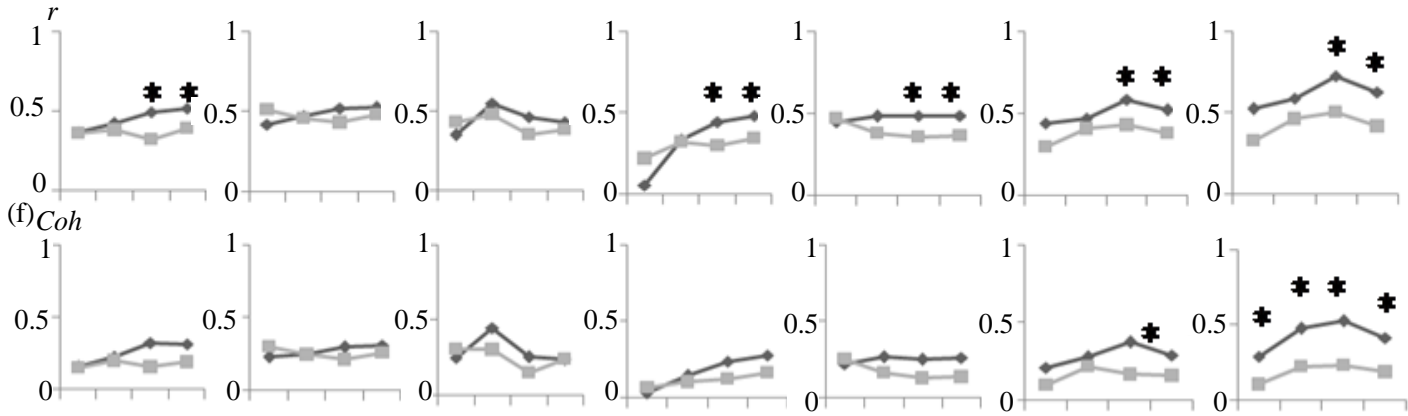

Figure 3. Values of right INTRA $r$ and coh (Fp2 - F4 [a y b], Fp2 - P4 [c y d], and F4 - P4 [e y f],) in all bands in the four conditions: eyes closed (EC), eyes open (EO), and during performance of the Hanoi (HA) and Wisconsin (WI) tasks in both evaluations. $* \geq 40 \%$ compared to evaluation 1 .

or some other causes. But the fact that she had a low score on the digits in progression sub-test on E-1 but not $\mathrm{E}-2$ could indicate that when the rape event was recent (E-1), her short-term memory or auditory attention was affected.

With respect to the EEG results, in general, significant decreases in the INTER-frontal (Fp1 - Fp2, F3 - F4,), INTRA-fronto-frontal (Fp1 - F3, Fp2 - F4) and fronto-parietal (Fp1 - P3, Fp2 - P4, F3 - P3, F4 - P4) $r$ and coh were found on E-2 with respect to E-1.

Normal developmental studies have described an overall INTRA coh increase around 14 - 15 years of age (when we performed E-I and E-2, respectively) in both hemispheres [41] [42]. These data show that in Yatzil's case, INTRA $r$ and coh followed a developmental pattern distinct from the norm, such that despite her lower synchronization among cortical areas in the same hemisphere, she was able to manifest adequate, normal execution on most of the neuropsychological and cognitive tests applied.

With respect to the degree of inter-hemispheric synchronization, the results of this study agree with other works that have reported $r$ and coh changes at these ages mainly in frontal, but not parietal areas [41]. Although a decrease in the coherence of the frontal lobes over time has been reported [42], the magnitude of change mentioned was not as large as that found in our study $(\geq 40 \%)$, nor was it apparent in this short-time period ( 1 year, 4 
months). It is probable that this rapid decrease in cortical synchronization is associated with a rearrangement of the cortical connections that allowed an adaptation to the external and internal environments despite the rape events.

It has been proposed that decreased coherence is associated with increased spatial differentiation, greater brain complexity and, therefore, increased speed and efficiency of information processing [45]. Similarly another study [46] reported that the average connection density of the brain decreases with a concomitant rise in brain size and complexity, reflecting an increasingly modular architecture. In this context a study [47] found that decreased coherence was positively correlated with IQ and hypothesized that general intelligence is positively correlated with faster processing times in the frontal connections, which is reflected in shorter phase delays, so that a decreased inter-hemispheric synchronization could be suggested as an index of cognitive effectiveness. Thus, the fact that Yatzil had decreased INTER $r$ and coh on E-2 could be associated with an accelerated maturation process that might be required for efficient performance on most of the neuropsychological and cognitive tests and for adequate behavioral adaptation in different areas of Yatzil's life.

Another interpretation related to the decrease of frontal INTER $r$ and coh on E-2 could involve maturation of the corpus callosum. It is well known that this area is the main connection pathway between the two hemispheres; hence, its integrity depends on the degree of functional coupling between the two halves. It has been shown that INTER coh is positively correlated with the regional corpus callosum [48] and studies have demonstrated that the development of the corpus callosum in both rodents and primates is negatively influenced by social adversity [49]-[51] as in cases of abused human children [52]-[54]. Likewise other study [26] found that mistreated adolescents showed reduced frontal (anterior) INTER coh. Thus, in this study it is probable that the decreased $r$ and coh between frontal regions obtained on E-2 is associated with the effect that the rape produced on the functionality of the corpus callosum that, as a result, decreased the degree of communication between the frontal cortices.

According to the literature, rape generates significant behavioral, emotional and cognitive alterations; however, this work shows that Yatzil, despite suffering two rapes, had few manifestations of psychopathological symptoms or cognitive impairments. This could be a result of the high level of resilience that she developed. On the other hand, over a short-period time, she showed an evident decrease in inter-cortex synchronization (frontal INTER and INTRA $r$ and coh), a significant indicator of cerebral maturation. It is possible that this "faster maturation" in some way changed Yatzil's perceptions of the world and determined many of the important decisions that she has taken during her lifetime.

The present study had several limitations. First, we do not have some information about any evaluation or the overall impact after the first rape experienced by Yatzil, which would be very valuable to this study. Second, we consider that the results presented in this study are not necessarily the consequences of the second rape; however, considering that other studies have reported the traumatic experiences such as that rape should have a significant impact on brain development, it is likely that the experiences of rape experienced by the adolescent evaluated in this study are closely related to our results, especially the EEG results. Third, it would have been good to register a participant with similar characteristics to Yatzil, however we were not able to recontact some female adolescents evaluated in a first session.

The case presented in this study reflects the variety of consequences that may arise from rape experiences, and emphasizes the importance of considering the difficulty of talking about the specific consequences of sexual violence - especially rape - which depends on various factors, including the circumstances of the event, its duration, and the victim's age, personality, etc. It is probable that in many cases the assessments used to evaluate individuals who have experienced sexual violence may produce incomplete results or diagnoses, or give false evidence of the effects of these experiences. Hence, more research needs to be done on the consequences of the experience of rape to produce data that will be essential to determining both the effects of rape and the most suitable treatments for these cases.

\section{Acknowledgements}

The authors thank Dr. Javier Álvaro Barriga Marín, Chief of Emergency Pediatrics and Coordinator of the Multidisciplinary Group for Child Victims of Abuse at the Civil Hospital "Dr. Juan I. Menchaca”, Guadalajara, Jalisco, Mexico, and the psychologist Leticia Guadalupe Casillas González for the facilities provided for assessing the adolescent discussed in this study. 


\section{References}

[1] Krug, E.G., Dahlberg, L.L., Mercy, J.A., Zwi, A.B. and Lozano, R. (2002) World Report on Violence and Health. World Health Organization, Geneva.

[2] Koss, M.P., Gidycz, C.A. and Wisniewski, N. (1987) The Scope of Rape: Incidence and Prevalence of Sexual Aggression and Victimization in a National Sample of Higher Education Students. Journal of Consulting and Clinical Psychology, 55,162-170. http://dx.doi.org/10.1037/0022-006X.55.2.162

[3] Koss, M.P. (1993) Detecting the Scope of Rape: A Review of Prevalence Research Methods. Journal of Interpersonal Violence, 8, 198-222. http://dx.doi.org/10.1177/088626093008002004

[4] Vicary, J.R., Klingaman, L.R. and Harkness, W.L. (1995) Risk Factors Associated with Date Rape and Sexual Assault of Adolescent Girls. Journal of Adolescence, 18, 289-306. http://dx.doi.org/10.1006/jado.1995.1020

[5] Mills, C.S. and Granoff, B.J. (2002) Date and Acquaintance Rape among a Sample of College Students. Social Work, 37, 504-509.

[6] Browne, A. and Finkelhor, D. (1986) Impact of Child Sexual Abuse: A review of the research. Psychological Bulletin, 99, 66-77. http://dx.doi.org/10.1037/0033-2909.99.1.66

[7] Bagley, C. and Shewechuk-Dann, D. (1991) Characteristics of 60 Children and Adolescents Who Have a History of Sexual Assault against Others: Evidence from a Controlled Study. Journal of Child and Youth Care, 3, 43-52.

[8] Conte, J. and Schuerman, J.R. (1987) Factors Associated with an Increased Impact of Child Sexual Abuse. Child Abuse Neglect, 11, 201-211. http://dx.doi.org/10.1016/0145-2134(87)90059-7

[9] Caffaro-Rouget, A., Lang, R.A. and van Santen, V. (1989) The Impact of Child Sexual Abuse on Victims’ of Adjustment. Annals of Sex Research, 2, 29-47. http://dx.doi.org/10.1007/BF00850678

[10] Paolucci, E.O., Genuis, M.L. and Violato, C.A. (2001) A Meta-Analysis of the Published Research on the Effects of Child Sexual Abuse. The Journal of Psychology, 135, 17-36. http://dx.doi.org/10.1080/00223980109603677

[11] Andersen, S.L., Tomoda, A., Vincow, E.S., Valente, E., Polcari, A. and Teicher, M.H. (2008) Preliminary Evidence for Sensitive Periods in the Effect of Childhood Sexual Abuse on Regional Brain Development. The Journal of Neuropsychiatry and Clinical Neurosciences, 20, 292-301. http://dx.doi.org/10.1176/appi.neuropsych.20.3.292

[12] De Kloet, E.R., Vreugdenhil, E., Oitzl, M.S. and Joels, M. (1998) Brain Corticosteroid Receptor Balance in Health and Disease. Endocrine Reviews, 19, 269-301.

[13] Timko, C.H., Katherine, W., Stovel, K.W., Baumgartner, M. and Moos, R.H. (1995) Acute and Chronic Stressors, Social Resources, and Functioning among Adolescents with Juvenile Rheumatic Disease. Journal of Research on Adolescence, 5, 361-385. http://dx.doi.org/10.1207/s15327795jra0503_4

[14] Mazure, C.M. and Maciejewski, P.K. (2003) A Model of Risk for Major Depression: Effects of Life Stress and Cognitive Style Vary by Age. Depression and Anxiety, 17, 26-33. http://dx.doi.org/10.1002/da.10081

[15] Glass, D.C., Reim, B. and Singer, J.E. (1971) Behavioral Consequences of Adaptation to Controllable and Uncontrollable Noise. Journal of Experimental Social Psychology, 7, 244-257. http://dx.doi.org/10.1016/0022-1031(71)90070-9

[16] Teicher, M.H., Glod, C.A., Surrey, J. and Swett, C. (1993) Early Childhood Abuse and Limbic System Ratings in Adult Psychiatric Outpatients. The Journal of Neuropsychiatry and Clinical Neurosciences, 5, 301-306.

[17] Heim, C., Newport, D.J., Heit, S., Graham, Y.P., Wilcox, M., Bonsall, R., Miller, A.H. and Nemeroff, C.B. (2000) Pituitary-Adrenal and Autonomic Responses to Stress in Women after Sexual and Physical Abuse in Childhood. Journal of the American Medical Association, 284, 592-597. http://dx.doi.org/10.1001/jama.284.5.592

[18] Bremner, J.D., Randall, P., Vermetten, E., Staib, L., Bronen, R.A., Mazure, C., Capelli, S., McCarthy, G., Innis, R.B. and Charney, D.S. (1997) Magnetic Resonance Imaging-Based Measurement of Hippocampal Volume in Posttraumatic Stress Disorder Related to Childhood Physical and Sexual Abuse: A Preliminary Report. Biological Psychiatry, 41, 23-32. http://dx.doi.org/10.1016/S0006-3223(96)00162-X

[19] Ito, Y., Teicher, M.H., Glod, C.A. and Ackerman, E. (1998) Preliminary Evidence for Aberrant Cortical Development in Abused Children: A Quantitative EEG Study. Journal of Neuropsychiatry and Clinical Neurosciences, 10, 298-307.

[20] Bremner, J.D., Narayan, M., Staib, L.H., Southwick, S.M., McGlashan, T. and Charney, D.S. (1999) Neural Correlates of Memories of Childhood Sexual Abuse in Women with and without Posttraumatic Stress Disorder. The American Journal of Psychiatry, 156, 1787-1795.

[21] Bremner, J.D., Vythilingam, M., Vermetten, E., Southwick, S.M., McGlashan, T., Staib, L.H., Soufer, R. and Charney, D.S. (2003) Neural Correlates of Declarative Memory for Emotionally Valenced Words in Women with Posttraumatic Stress Disorder Related to Early Childhood Sexual Abuse. Biological Psychiatry, 53, 879-889. http://dx.doi.org/10.1016/S0006-3223(02)01891-7

[22] Shaw, J.C. (1981) An Introduction to the Coherence Function and Its Use in EEG Signals Analysis. Journal of Medical 
Engineering \& Technology, 5, 279-288. http://dx.doi.org/10.3109/03091908109009362

[23] Shaw, J.C. (1984) Correlation and Coherence Analysis of the EEG: A Selective Tutorial Review. International Journal of Psychophysiology, 1, 255-266. http://dx.doi.org/10.1016/0167-8760(84)90045-X

[24] Guevara, M.A. and Corsi-Cabrera, M. (1996) EEG Coherence or EEG Correlation? International Journal of Psychophysiology, 23, 145-153. http://dx.doi.org/10.1016/S0167-8760(96)00038-4

[25] Ito, Y., Teicher, M.H., Glod, C.A., Harper, D., Magnus, E. and Gelbard, H.A. (1993) Increased Prevalence of Electrophysiological Abnormalities in Children with Psychological, Physical, and Sexual Abuse. Journal of Neuropsychiatry and Clinical Neurosciences, 5, 401-408.

[26] Miskovic, V., Schmidt, L.A., Georgiades, K., Boyle, M. and Macmillan, H.L. (2010) Adolescent Females Exposed to Child Maltreatment Exhibit Atypical EEG Coherence and Psychiatric Impairment: Linking Early Adversity, the Brain, and Psychopathology. Development and Psychopathology, 22, 419-432. http://dx.doi.org/10.1017/S0954579410000155

[27] Miskovic, V., Schmidt, L.A., Georgiades, K., Boyle, M. and MacMillan, H.L. (2009) Stability of Resting Frontal Electroencephalogram (EEG) Asymmetry and Cardiac Vagal Tone in Adolescent Females Exposed to Child Maltreatment. Developmental Psychobiology, 51, 474-487. http://dx.doi.org/10.1002/dev.20387

[28] Yasik, A.E., Saigh, P.A., Oberfield, R.A. and Halamandaris, P.V. (2007) Post-Traumatic Stress Disorder: Memory and Learning Performance in Children and Adolescents. Biological Psychiatry, 61, 382-388. http://dx.doi.org/10.1016/j.biopsych.2006.06.005

[29] Beers, S.R. and De Bellis, M.D. (2002) Neuropsychological Function in Children with Maltreatment-Related Posttraumatic Stress Disorder. American Journal of Psychiatry, 159, 483-486. http://dx.doi.org/10.1176/appi.ajp.159.3.483

[30] Wechsler, D. (1974) Manual for the Wechsler Intelligence Scale for Children-Revised. The Psychological Corporation, San Antonio.

[31] Oldfield, R.C. (1971) The Assessment and Analysis of Handedness: The Edinburgh Inventory. Neuropsychologia, 9, 97-113. http://dx.doi.org/10.1016/0028-3932(71)90067-4

[32] Bryden, M.P. (1977) Measuring Handedness with Questionnaires. Neuropsychologia, 15, 617-624. http://dx.doi.org/10.1016/0028-3932(77)90067-7

[33] Matute-Villaseñor, E., Roselli, M., Ardila, A. and Ostrosky-Solís, F. (2007) Evaluación Neuropsicológica Infantil (ENI). Manual Moderno, México.

[34] Guevara, M.A., Rizo, L., Ruiz-Díaz, M. and Hernández-González, M. (2009) HANOIPC3: A Computer Program to Evaluate Executive Functions. Computer Methods and Programs in Biomedicine, 95, 158-165. http://dx.doi.org/10.1016/j.cmpb.2009.02.007

[35] Jasper, H.H. (1958) The Ten-Twenty Electrode System of the International Federation. Electroencephalography and Clinical Neurophysiology, 10, 371-375.

[36] Guevara, M.A., Ramos, J., Hernández-González, M., Madera, H. And Corsi-Cabrera, M. (2000) CAPTUSEN: A System for the Computerized Acquisition of EEG and Event-Related Potentials. Revista Mexicana de Psicología, 17, 7788.

[37] Guevara, M.A., Hernández-González, M. and Sanz-Martín, A. (2010) CHECASEN: Programa para revisar señales EEG fuera de línea. Revista Mexicana de Ingeniería Biomédica, 31, 135-141.

[38] Guevara, M.A., Hernández-González, M., Zarabozo, D. and Corsi-Cabrera, M. (2003) POTENCOR: A Program to Calculate Power and Correlation Spectra of EEG Signals. Computer Methods and Programs in Biomedicine, 72, 241250. http://dx.doi.org/10.1016/S0169-2607(02)00128-1

[39] Hickling, E.J. and Blanchard, E.B. (1997) The Private Practice Psychologist and Manual-Based Treatment: A Case Study in the Treatment of Post-Traumatic Stress Disorder Secondary to Motor Vehicle Accidents. Behaviour Research and Therapy, 35, 191-203. http://dx.doi.org/10.1016/S0005-7967(96)00090-3

[40] American Psychiatric Association (2000) Diagnostic and Statistical Manual of Mental Desorders. 4th Edition, American Psychiatric Publishing, Washington DC.

[41] Thatcher, R.W., Walker, R.A. and Guidice, S. (1987) Human Cerebral Hemispheres Develop at Different Rates and Ages. Science, 236, 1110-1113. http://dx.doi.org/10.1126/science.3576224

[42] Marosi, E., Harmony, T., Sanchez, L., Becker, J., Bernal, J., Reyes, A., Díaz de León, A.E., Rodríguez, M. and Fernández, T. (1992) Maturation of the Coherence of EEG Activity in Normal and Learning disabled Children. Electroencephalography and Clinical Neurophysiology, 83, 350-357. http://dx.doi.org/10.1016/0013-4694(92)90070-X

[43] Mullen, P.E., Romans-Clarkson, S.E., Walton, V.A. and Herbison, G.P. (1998) Impact of Sexual and Physical Abuse on Women's Mental Health. Lancet, 1, 841-845.

[44] Masten, A.S. (1999) Resilience Comes of Age: Reflections on the Past and Outlook for the Next Generation of Re- 
search. In: Glantz, M.D., Johnson, J. and Huffman, L., Eds., Resilience and Development: Positive Life Adaptations, Plenum, New York, 282-296.

[45] Silberstein, R.B., Song, J., Nunez, P.L. and Park, W. (2004) Dynamic Sculpting of Brain Functional Connectivity Is Correlated with Performance. Brain Topography, 16, 249-254.

http://dx.doi.org/10.1023/B:BRAT.0000032860.04812.b1

[46] Ringo, J.L. (1991) Neuronal Interconnection as a Function of Brain Size. Brain, Behavior and Evolution, 38, 1-6. http://dx.doi.org/10.1159/000114375

[47] Thatcher, R.W., North, D. and Biver, C. (2005) EEG and Intelligence: Relations between EEG Coherence, EEG Phase Delay and Power. Clinical Neurophysiology, 116, 2129-2141. http://dx.doi.org/10.1016/j.clinph.2005.04.026

[48] Pogarell, O., Teipel, S.J., Juckel, G., Gootjes, L., Moller, T., Burger, K., Leinsinger, G., Moller, H.J., Hegerl, U. and Hampel, H. (2005) EEG Coherence Reflects Regional Corpus Callosumarea in Alzheimer's Disease. Journal of Neurology, Neurosurgery \& Psychiatry, 76, 109-111. http://dx.doi.org/10.1136/jnnp.2004.036566

[49] Sanchez, M.M., Hearn, E.F., Dung, D., Rilling, J.K. and Herndon, J.G. (1998) Differential Rearing Affects Corpus Callosum Size and Cognitive Function of Rhesus Monkeys. Brain Research, 812, 38-49. http://dx.doi.org/10.1016/S0006-8993(98)00857-9

[50] Berrebi, A.S., Fitch, R.H., Ralphe, D.L., Denenberg, J.O., Friedrich Jr., V.L. and Denenberg, V.H. (1988) Corpus Callosum: Region-Specific Effects of Sex, Early Experience and Age. Brain Research, 438, 216-224. http://dx.doi.org/10.1016/0006-8993(88)91340-6

[51] Denenberg, V.H. (1981) Hemispheric Laterality in Animals and the Effects of Early Experience. Behavioral and Brain Science, 4, 1-49.

[52] De Bellis, M.D., Keshavan, M.S., Clark, D.B., Casey, B.J., Giedd, J.N., Boring, A.M., Frustaci, K. and Ryan, N.D. (1999) Developmental Traumatology. Part II: Brain Development. Bennett Research Award. Biological Psychiatry, 45, 1271-1284. http://dx.doi.org/10.1016/S0006-3223(99)00045-1

[53] De Bellis, M.D., Keshavan, M.S., Shifflett, H., Iyengar, S., Beers, S.R., Hall, J. and Moritz, G. (2002) Brain Structures in Pediatric Maltreatment-Related Post-Traumatic Stress Disorder: A Socio Demographically Matched Study. Biological Psychiatry, 52, 1066-1078. http://dx.doi.org/10.1016/S0006-3223(02)01459-2

[54] Teicher, M.H., Dumont, N.L., Ito, Y., Vaituzis, C., Giedd, J.N. and Andersen, S.L. (2004) Childhood Neglect Is Associated with Reduced Corpus Callosum Area. Biological Psychiatry, 56, 80-85. http://dx.doi.org/10.1016/j.biopsych.2004.03.016 
Scientific Research Publishing (SCIRP) is one of the largest Open Access journal publishers. It is currently publishing more than 200 open access, online, peer-reviewed journals covering a wide range of academic disciplines. SCIRP serves the worldwide academic communities and contributes to the progress and application of science with its publication.

Other selected journals from SCIRP are listed as below. Submit your manuscript to us via either submit@scirp.org or Online Submission Portal.
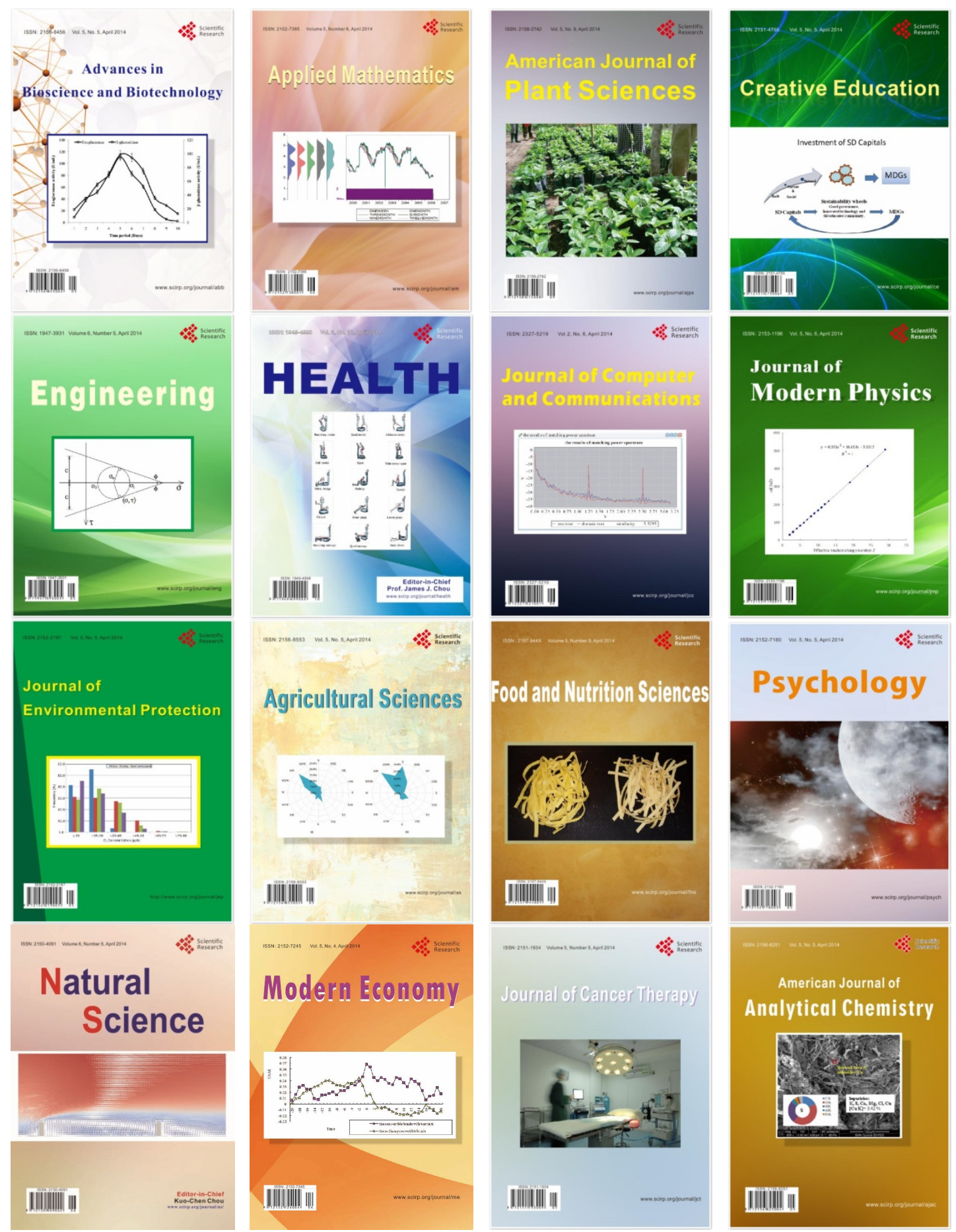